\section{ARCHIVOS}

de historia del movimiento obrero y la izquierda

\title{
En memoria de Silvana Staltari
}

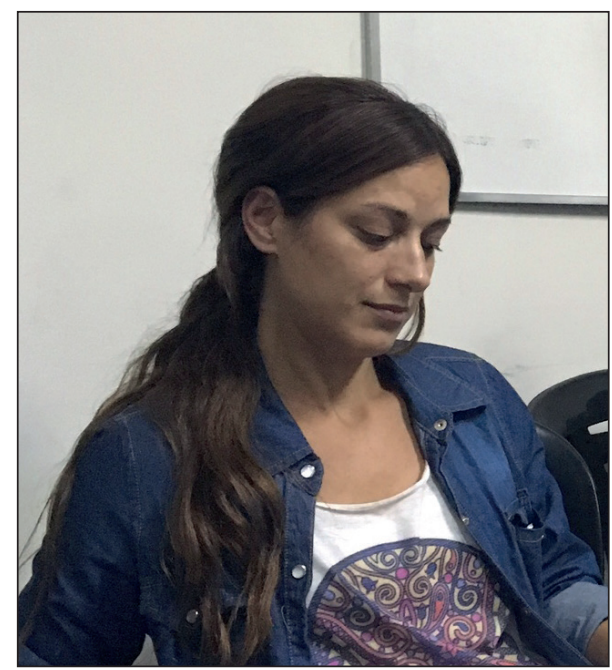

Silvana Andrea Staltari (1979-2021), integrante del CEHTI y la revista Archivos, falleció a sus 42 años el pasado 27 de junio tras una dura pelea contra el cáncer que duró poco más de tres años. Colega, amiga y compañera adorable, Silvana trabajó, como pudo, hasta sus últimos dias. Queremos reconocer su labor profesional como historiadora en estas páginas, al calor del cariño, el amor y el compromiso con el cual actuó en relación a sus semejantes y a su práctica en la investigación.

Su camino en el universo de la historia se inició en el Instituto Superior del Profesorado "Dr. Joaquín V. González". Ese paso le abrió las

DOI: https://doi.org/10.46688/ahmoi.n19.323

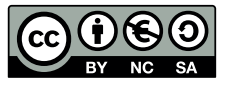

Obra bajo licencia Creative Commons 4.0 International (Atribución - NoComercial - Compartirlgual) 
puertas de la enseñanza que la llevaron durante años a ponerse al frente de innumerables cursos en escuelas secundarias públicas y privadas y en la Universidad Nacional de Lanús. Continuó sus estudios en la Universidad Nacional Tres de Febrero, en donde obtuvo la Licenciatura y, posteriormente, la Maestría en Historia. Hasta estos días, Silvana se encontraba realizando su tesis doctoral en la Facultad de Filosofia y Letras de la Universidad de Buenos Aires, bajo la dirección del Dr. Hernán Camarero.

A lo largo de su carrera definió su tema de investigación, objeto de estudio y recorte temporal en los que trabajó en sus distintas etapas de formación: el análisis de la política del Partido Comunista (PC) durante la década peronista (1946-1955). Comenzó a interesarse por el comunismo argentino en la carrera de grado, en donde planteó las bases de su interrogación acerca de aquel fragmento de la realidad sociohistórica: si el peronismo obtuvo el apoyo mayoritario de la clase obrera, ¿qué sucedió con el vínculo que esta tenía con uno de sus principales representantes en las etapas previas a 1945-1946? Esa primera pregunta general -que refleja el espíritu científico, aquel que se asoma desde la duda, la incerteza o el vacío para elaborar respuestas producto de la interpretación, aquel que se construye desde la imaginación creativa y artesanal- fue ganando densidad y afinándose con el crecimiento profesional de Silvana.

La tesis de licenciatura fue el primer trabajo en el que expuso sus aportes (Staltari, 2014a). Allí se centró en el estudio de los posicionamientos del partido frente a la politica social desarrollada por el gobierno, en tanto entendió que la misma era una de las dimensiones en las que se jugó la construcción de los apoyos de las masas trabajadoras y el surgimiento de una identidad peronista. Para realizarlo, se centró en el análisis del XI Congreso partidario, el cual fijó las bases del accionar comunista en aquellos años y cuyo texto se convirtió en un insumo nodal de sus investigaciones. El foco puesto en la demagogia y en la falta de experiencia de una "nueva" clase obrera, la diferenciación entre sectores reaccionarios y progresistas, fueron algunos de los elementos que llevaron al PC a alternar una politica de apoyo a las medidas favorables a la clase obrera en combinación con el rechazo a aquellas nocivas, política que tenía como objetivo evidenciar la naturaleza contradictoria del peronismo y atraer así a trabajadores y trabajadoras. La pesquisa sumó su aporte al demostrar que el PC no había quedado estático por su paso por la Unión Democrática, sino que inauguró, tempranamente, su política de acercamiento al peronismo en general y a la clase obrera identificada con este en particular.

La continuación de este trabajo la llevó a explorar en la maestría los posicionamientos y las prácticas políticas del mismo partido pero en 
el periodo siguiente, recortado entre 1955 y 1962, es decir, durante la autodenominada "Revolución Libertadora" y el posterior gobierno radical de Arturo Frondizi (Staltari, 2017). Se trata de una de las líneas menos conocidas de su recorrido ya que, pensando en su doctorado, eligió seguir dedicándose a los años peronistas. Sin embargo, la tesis presentada significó un gran aporte para la sistematización de los lineamientos principales del comunismo ingresando a la segunda mitad del siglo XX a través de un enfoque centrado en las rupturas y continuidades de su política tras el corte de 1955. Advirtió allí que el planteo frentista aplicado tras el golpe de Estado reproducía esquemas ya elaborados en ocasión del ascenso de Perón, lo cual puede ser una de las claves para comprender el retorno de Silvana hacia esos orígenes.

Hacia 2015, su camino profesional dio un salto. El deseo de continuar con la investigación se combinó con su participación en la gestación del espacio que luego se constituyó como CEHTI. Activa, siempre atenta y bien predispuesta a las necesidades que surgieron en los primeros años de construcción de este proyecto, se puso a cargo del diseño de los boletines informativos, de la coordinación y difusión de las actividades junto a otros y otras compañeros/as, y se sumó constantemente a diversas iniciativas del colectivo, especialmente a la creación de la Biblioteca-Archivo del centro de estudios. La solidaridad con sus compañeros y compañeras y su dedicación fueron un sello inalterable en el rol que jugó como una de las fundadoras de este espacio y de la asociación civil.

La experiencia adquirida en la profesión y el lazo entablado con los y las colegas del CEHTI le permitió bucear con mayor profundidad las características que asumió la intervención del comunismo, adentrándose en la complejidad que implicaba la adopción de diversas formas de interpelación y en las dificultades que afrontó por ello la militancia encargada de difundir el marxismo leninismo en las filas del peronismo obrero (Staltari, 2014b). Y, en ese problema, Silvana encontró el proyecto para su doctorado. ¿Cuál fue el proceder del PC en el mundo sindical que se formó a partir del ascenso de Perón? ¿Cómo desarrolló su estrategia sindical a partir de 1946? Más aún, ¿cuál había sido esa estrategia entre 1943 y 1946? Esta última pregunta guió el análisis que realizó sobre la manera como el golpe militar interrumpió el crecimiento que el comunismo venía sosteniendo en los sindicatos desde décadas previas. Sopesando factores endógenos y exógenos, el estudio realizado se fijó en los intentos del PC por contrarrestar esa situación a partir del análisis de distintos niveles de su intervención, desde la creación de instituciones que aglutinaran a sectores opuestos al gobierno, el restablecimiento de las funciones de las organizaciones sindicales en las que tenian presencia y el trabajo de base al interior de los espacios laborales, los cuales resultaron infructuosos (Ceruso y Staltari, 2018). 
En base a esta evaluación, el último avance que pudo publicar estuvo dedicado a los cambios de la estrategia sindical del comunismo tras el triunfo de Perón en 1946 y la forma en que estos se aplicaron en los gremios en los que el PC tenía mayor incidencia, como fue el caso de la carne, textil, metalúrgico, alimentación, construcción y vestido, entre otros. De este modo, se ocupó de estudiar un terreno inexplorado, caracterizado por la transición efectuada por el sindicalismo comunista, desde la defensa de la independencia de los sindicatos en el gobierno militar de 1943-1946 hasta la disolución de estos para reforzar la unidad de las bases y estrechar lazos con los y las trabajadores y trabajadoras peronistas a partir de 1946 y de los lineamientos del XI Congreso partidario. El pasaje hacia la integración en los sindicatos reconocidos estatalmente se construyó como una dimensión relevante para entender no solo los términos de la construcción de la hegemonía peronista en el mundo obrero sino también para esclarecer algunos aspectos de la tensa relación que caracterizó, en las décadas siguientes, el vínculo entre el peronismo y las izquierdas en esa arena (Staltari, 2019).

Hasta el último de sus dias, Silvana trabajaba en un balance de las formas que adoptó la estrategia de Frente Popular en la década peronista, diferenciando su aplicación en los distintos espacios, principalmente el de la política nacional y el del movimiento obrero. Ese estudio, que pronto saldrá publicado, miraba el otro lado del eclipse. Silvana miraba, como hacemos el resto de sus compañeros y compañeras, la historia de quienes perdieron, de quienes sufrieron desplazamientos, persecuciones, encarcelamientos, despidos, sanciones; en suma, represalias de diversa índole. Silvana rastreaba dónde estaban, dónde estuvieron los sectores que no fueron parte de las victorias, qué hacían, cuáles eran sus móviles y fundamentos, realizando su trabajo de hormiga con espíritu crítico y, sobre todo, pasión por lo que hacía. A pesar de las complicaciones de salud, Silvana se aferró a la investigación y esa impronta está y seguirá estando en quienes la hemos acompañado durante estos tiempos dolorosos.

Colega, amiga, compañera, te extrañaremos y trataremos de mantener la llama viva de tus búsquedas, de tu línea de investigación, tus interrogantes y tus enfoques. A pesar del dolor indeleble, nos quedan tus aportes a la historiografia en general, a la historia de los y las de abajo en particular y la potencia de la construcción colectiva en nuestro espacio. Hasta siempre, Sil.

Ezequiel Murmis y Mercedes López Cantera 


\section{Referencias}

Staltari, S. (2014a). Los falsos apóstoles contra la demagogia peroniana: el Partido Comunista frente a la política social del peronismo, Investigaciones y Ensayos, 60, pp. 459-490.

Staltari, S. (2014b). El Partido Comunista frente al peronismo: estrategia y tácticas políticas, 1945-1955, Archivos de Historia del Movimiento Obrero y la Izquierda, III (5), pp. 11-30.

Staltari, S. (2017). El Partido Comunista de la Argentina frente al peronismo, 1955-1962: posicionamientos y prácticas politicas. Tesis de maestría (inédita), Universidad Nacional de Tres de Febrero.

Ceruso, D. y S. Staltari (2018). El Partido Comunista argentino y su estrategia sindical entre 1943 y 1946, Izquierdas, 39, abril, pp. 110-130.

Staltari, S. (2019). El Partido Comunista Argentino: su planteo sindical en los primeros años del gobierno peronista (1946-1948), Historia Regional. Sección Historia, ISP n ${ }^{\circ}$, Villa Constitución, XXXII (41), julio-diciembre, pp. $1-15$. 